\title{
Sublimação: imagens em transitividade
}

\begin{abstract}
Resumo
O presente artigo trata da impressão como uma etapa intermediária em processos de elaboração de imagens artísticas, abordando-se especificidades do processo de impressão por sublimação. Analisa também o caráter transitivo das imagens possibilitado pelas transferências agenciadas entre matriz e suporte de impressão, nos trabalhos de Lurdi Blauth, Eduardo Vieira da Cunha e Clóvis Vergara de Almeida Martins Costa. Na produção desses artistas detecta-se o emprego de procedimentos de impressão, descreve-se os diferentes modos de imprimir e suas implicações nas etapas de trabalho para a elaboração de linguagens como a pintura, gravura e fotografia. O referencial teórico articula o pensamento de Didi-Huberman a respeito da impressão como um paradigma antropológico que envolve a questão da transmissão permeada pelas relações entre duplo e semelhança e as definições de Edmund Couchot referentes à matriz numérica implicando a estrutura matriz-imagem e suas especificidades na transferência da realidade pré-existente.
\end{abstract}

Palavras-chave: Impressão. Matriz. Sublimação. Processos artísticos.

\section{Abstract}

The present article is about printing as an intermediate stage in artistical images elaboration processes, approaching the specificness of the sublimation printing process. It also analyses the image transitional character, made posssible by transferences created between the matrix and the printing surface in works of Lurdi Blauth, Eduardo Vieira da Cunha and Clóvis Vergara de Almeida Martins Costa.In these artists production, it is possible to detect the use of printing procedures; and the different ways of printing, as well as its implications in work steps taken for the elaboration of languages such as painting, engraving, and photography, are described. The theoretic references articulate DidiHuberman thought about printing as an anthropological paradigm that involves the matter of transmition permeated by the relations between double and similarity, and Edmund Couchot definitions regarding numerical matrix, implicating the matrix-image structure and its specificities in the pre-existing reality.

Key-words: Printing. Matrix. Sublimation. Artistical processes.

\section{Impressão por semelhança e contato: uma introdução}

A multiplicidade de tecnologias para impressão de imagens, na atualidade, faz refletir sobre a ideia de impressão e as possibilidades de criar imagens com o cruzamento de diferentes meios e procedimentos ${ }^{1}$. De um lado, percebemos que as técnicas de impressão vêm revestidas pelo tempo e pela memória, nas quais nem sempre o avanço tecnológico está presente. $E$, de outro, as fronteiras entre os meios estão cada vez mais imbricadas e constantemente redefinem parâmetros que provocam novos questionamentos na arte.

\footnotetext{
${ }^{1}$ Procedimentos de contato é uma pesquisa de concentração no campo artístico e experimental na área das Poéticas Visuais. Investiga a intersecção entre os procedimentos de contato empregados em técnicas tradicionais de reprodução da imagem e os desdobramentos possibilitados a tais imagens quando convertidas em dados numéricos. São estudadas as implicações conceituais geradas pelo emprego da imagem numérica no estatuto da imagem fotográfica nos processos artísticos contemporâneos.
} 
No entendimento de Didi-Huberman, o gesto de fazer impressões remete a "um gesto técnico" que nos indica um campo operatório que nos leva a pensar sobre o paradigma da impressão. Para este autor, "a impressão supõe um gesto que se cumpre em um ato. Um gesto que dá margem a uma marca durável e um resultado mecânico que resulta em negativo ou em um relevo. Trata-se, então, de um dispositivo técnico completo" (2008, p. 27).

Os diferentes procedimentos de impressão correspondem, geralmente, ao processo de reproduzir de maneira inversa o que está gravado na matriz e as imagens revelam as especificidades desse fazer. Por sua vez, essas operações vão além do controle técnico e as impressões podem ser resultantes de um gesto direcionado, de uma ação casual, de meios rudimentares ou mesmo provenientes de técnicas mais elaboradas. Os meios de impressão envolvem,

[...] uma espécie paradoxal de eficiência e magia: magia que seria aquela singular tomada do corporal universalizante como a reprodução serial, a que produz semelhanças extremas que não são mimeses, mas duplicação ou ainda, a de produzir semelhanças como negativos, contra-formas, dessemelhanças (DIDIHUBERMAN, 1997, p.3).

O duplo que se origina da impressão pode ser caracterizado como um dispositivo fiel de reproduzir e conservar a referência de uma imagem gravada sobre uma matriz. Nessa ação de imprimir, acontece o encontro entre duas superfícies, as quais devem aderir para operar o contato de um corpo sobre outro, permitindo que sejam transmitidas fisicamente semelhanças aproximadas da imagem retida sobre a matriz. É nesse movimento de apreender e reproduzir que a impressão incorpora aprisionamentos e perdas, aproximações e afastamentos, gerando pontos de contato entre matriz e suporte. Nesse sentido, "a impressão envolve duas questões fundamentais: de um lado é um procedimento aberto à experimentação, que permite inúmeras inserções e alterações, e, de outro, é um meio que possibilita a captura e a apreensão de algo que resulta numa semelhança" (BLAUTH, 2011, p. 52).

Nas impressões de matrizes tradicionais (xilo e metal, por exemplo), deparamonos com a previsibilidade da imagem gravada, bem como com os seus acasos e aspectos imprevisíveis. Num primeiro momento, percebemos a duplicação de uma semelhança, porém o que ocorre são diferenças entre áreas gravadas e não gravadas. "O côncavo resulta no convexo e o convexo resulta no côncavo e, mesmo tendo equivalências nas semelhanças, ocorrem as diferenças e, por isso, talvez, acontece esse processo mágico e singular no momento da transposição da imagem pela impressão" (BLAUTH, 2011, p.54).

Para Didi-Huberman, a impressão é um paradigma antropológico e coloca a questão de transmissão. A impressão procede da reprodução que remete à gênese da forma e da contraforma, que, pela semelhança, transmite e duplica as marcas e as mensagens 
gravadas sobre uma matriz. A impressão transmite fisicamente e não apenas visualmente a semelhança de algo gravado sobre uma matriz, ou seja, surge enquanto corpo produzido pela operação da impressão.

Nesse processo, as impressões são resultantes do contato com uma matriz. O que é então uma matriz? Anotamos algumas designações: do latim matrix: lugar onde algo se gera ou se cria; órgão das fêmeas dos mamíferos onde se gera o feto, útero; clichê; molde de metal para fundição de tipos; contramolde de gesso, cera; fonte ou origem (FERREIRA, 1986 apud BLAUTH, 2011, p. 36). A matriz nos fala do lugar onde se forma, coagula-se a semelhança, ela nos ensina o que pode vir a ser uma forma nova (DIDIHUBERMAN,1997). Ou seja, "num sentido amplo, a matriz tem a função de ser o espaço gerador e simultaneamente ser a condutora da imagem para ser reproduzida sobre um suporte, mediante pressão" (BLAUTH, 2011, p. 37).

A interpenetração entre impressão e matriz envolve a produção de imagens que podem ser capturadas através de gestos elementares, como as frotagens de texturas de um assoalho, por exemplo, a produção de marcas de corpos na areia, traços no chão, ou manchar/marcar a superfície de uma tela com terra, sangue, ou mesmo detritos recolhidos ao acaso na beira de um rio.

Os procedimentos oriundos da gravura em metal (calcogravura), por exemplo, implicam no contato entre matriz e suporte, cujas impressões resultam entre áreas de sulcos gravados e não gravados. Na série denominada de Passagens entre Paisagens, Lurdi Blauth utiliza a fotografia digital para capturar imagens de paisagens a partir da janela de um carro em movimento, cujos dados icônicos são entrecruzados com diferentes meios, passando pela imagem numérica, pela gravação e impressão física e, depois, retornam novamente para o numérico (Figuras 1 e 2 ). 


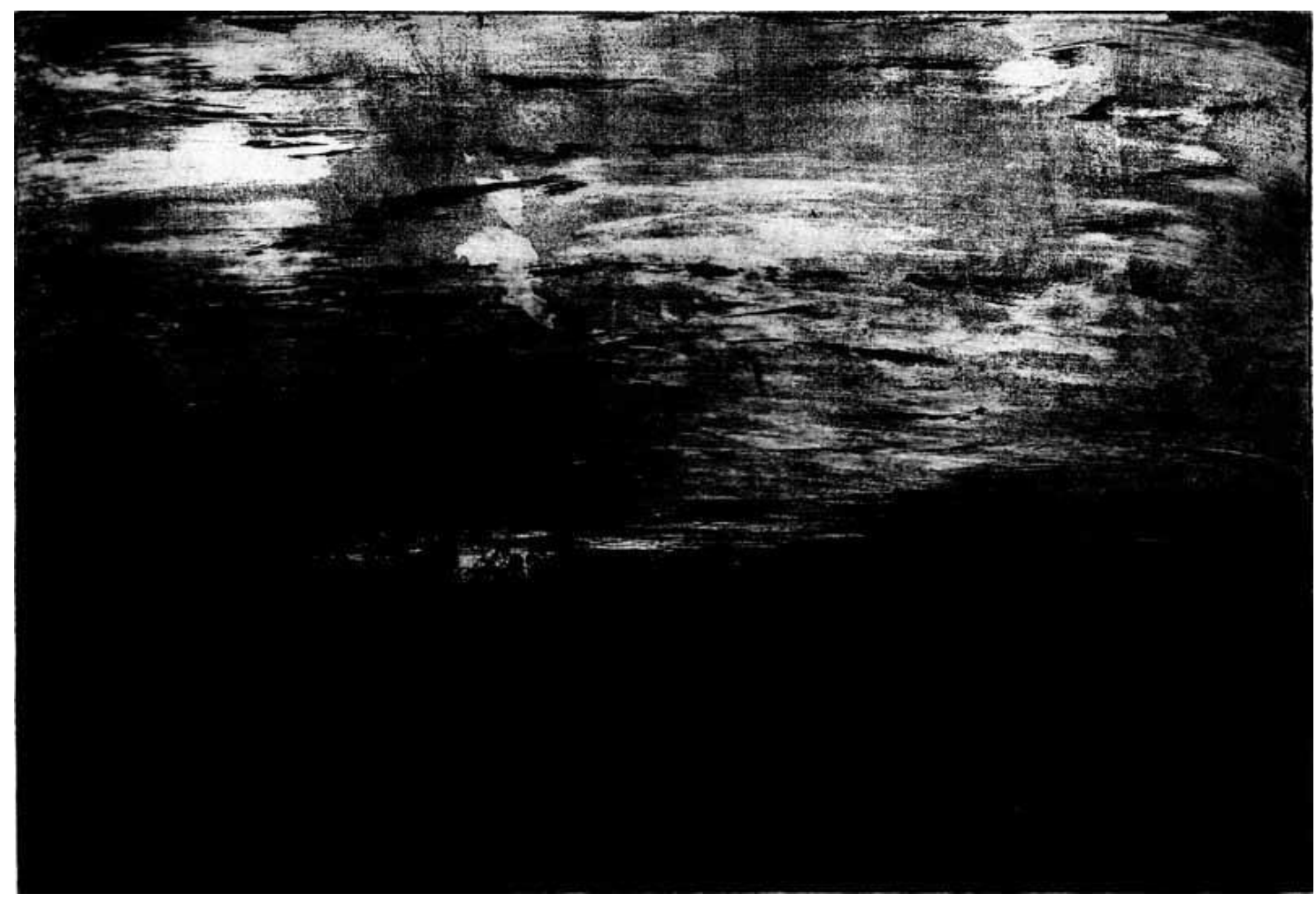

Figura 1. Passagem VIII. 2012. Fotogravura digital, $70 \times 48 \mathrm{~cm}$.

Num primeiro momento, a imagem fotografada passa por tratamentos no computador, acentuando-se determinados contrastes para que se possa dar continuidade a novas alterações nas etapas seguintes e processar a sua transmissão sobre outros suportes. Nessa operação, já constatamos que "a imagem numérica se apresenta como uma matriz com duas dimensões de pontos elementares: os pixels. [...] O pixel faz o papel de permutador - minúsculo - entre a imagem e o número [...]. Ou seja, a imagem tornase uma imagem-matriz" (COUCHOT, 2003, p.161).

Essa imagem-matriz é impressa em uma impressora doméstica para, depois, passar por processos manuais de transferência para placas de metal. Nesse processo de transmissão de um suporte flexível (o papel) para o rígido, que é a placa de cobre, já podemos perceber significativas modificações na cena, pois não há um controle de uma duplicação exata da mesma, o que interessa é capturar certos traços que remetem a vestígios de paisagem. A seguir, a placa é trabalhada com a técnica da água tinta, que consiste em pulverizá-la com resina, que é fixada através do calor para, depois, receber banhos de ácido. Essa resina cria uma infinidade de minúsculos pontos sobre as matrizes de cobre, criando áreas protegidas que não são atingidas pelo ácido. No entanto, pela sucessão da aplicação da resina e de banhos sucessivos de ácidos, esses pontos se sobrepõem e se intensificam em sulcos gravados, assim, no momento da intermediação da tinta, revelam resquícios de paisagens entre áreas negras e densas nas imagens impressas. 




Figura 2. Passagem IX. 2012. Fotogravura digital, $70 \times 48 \mathrm{~cm}$.

$\mathrm{Na}$ etapa seguinte, as matrizes são impressas de modo convencional - em uma prensa de gravura e com tinta de impressão, depois, as imagens são escaneadas e inseridas no computador para novamente serem alteradas. Essas imagens impressas são duplicadas, tornando possível efetuar novas intervenções e manipulações devido à estrutura matricial da imagem constituída pelos pixels. Gera-se novamente a imagemmatriz, cujos dados numerizados, ao serem colocados em memória, podem ser duplicados e transmitidos indefinidamente sobre diversos suportes físicos e impressos em diferentes dimensões.

\section{Impressão: uma etapa transitiva na pintura}

O artista Eduardo Vieira da Cunha trabalha com a transferência de imagens de uma forma não tecnológica, empregando o princípio de matrizes entintadas, como uma etapa de seu trabalho em pintura. Em entrevista recente, descreve como isso se dá em seu processo de ateliê.

\footnotetext{
"A gravura integrou meu trabalho na forma de transferências de imagens, sejam elas de matrizes fotográficas ou de matrizes diversas, como a impressão através do decalque. Eu sempre utilizei esse princípio de transferência em minha pintura. Acho que é fundamental considerar um princípio, levando em
} 
conta o termo contato, que é o que vocês utilizam nessa pesquisa, e que se relaciona com meu trabalho: considero a superfície da minha pintura como uma superfície sensível, como se fosse uma superfície fotográfica, que retém as formas". 2

Nas impressões por contato direto citadas por Vieira da Cunha estão presentes as marcas, rastros, relevos e texturas. A noção de transferência está impregnada pela conexão matérica entre dois corpos físicos.

Segundo Schaeffer (1996, p.16), "a impressão é um traço que um corpo físico imprime sobre ou em outro corpo físico". O autor faz a distinção entre as impressões por contato direto e as impressões a distância. No caso da gravura, a impressão é o efeito de uma ação mecânica ou química que ocorre de forma direta do material impregnante sobre o corpo impresso. O mesmo ocorre com as monotipias, os decalques e os carimbos. As impressões de contato direto ou a distância podem resultar no trabalho final do artista e também funcionam como etapas intermediárias na elaboração das imagens. Para Shaeffer (1996), nas impressões a distância (que é o caso da fotografia em laboratório), há a exigência de um elemento físico intermediário (a luz) entre o material impregnante (o negativo) e a impressão (no papel) que provoca uma tensão espacial a qual implica na ausência do contato direto entre o impregnante e a impressão. $\mathrm{E}$, nesse sentido, o distanciamento provoca uma ruptura.

Empregando o princípio da impressão por contato direto por meio do decalque (com o uso de máscaras e/ou carimbos) Eduardo Vieira da Cunha conta com a ocorrência de acasos durante o contato do impregnante sobre o corpo impresso "o contato de um pano, molhado de tinta, sobre a tela, onde fica gravada uma imagem, ou marca", a matriz física provoca resultados distintos de acordo com a variação do entintar e da pressão exercida sobre o suporte. Vieira da Cunha destaca nesse fazer a relação entre presença e ausência, "O contato tem tudo a ver com a impressão: é uma presença que aponta para uma ausência. Ali nesse contato, e no que ele produz depois de encostar em algo, é uma impressão, um registro de uma ausência: a ausência do referente, a presença de sua marca, de sua impressão". 3

Em sua pintura, as impressões são um recurso empregado numa ou outra etapa do fazer pictórico. Auxiliam as operações de repetição de elementos que compõem o quadro. A ausência é preenchida, transformada, acrescida de detalhes. Cada figura decalcada é tratada individualmente, com sua textura, seu grafismo, como se fosse vista com uma lupa (Figura 3).

\footnotetext{
2 Entrevista concedida à Paula Leiria Pressler, Porto Alegre, em novembro de 2011.

${ }^{3}$ Entrevista concedida à Paula Leiria Pressler, Porto Alegre, em novembro de 2011. 


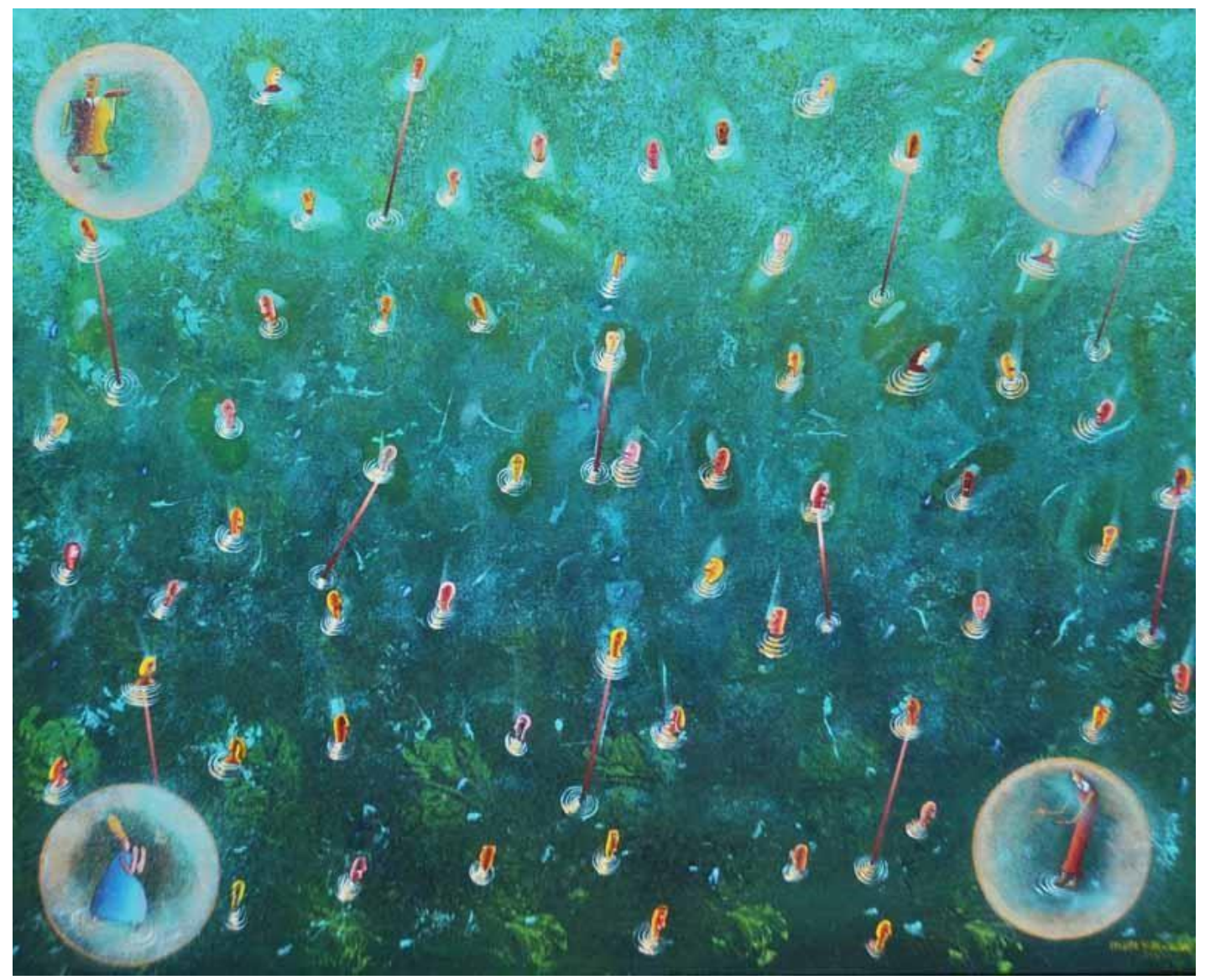

Figura 3. Cabeças. 2011. Acrílico sobre tela, $80 \times 100 \mathrm{~cm}$.

Os objetos que permeiam seu imaginário, postos na tela, fazem-nos relacionar a impressão como etapa ao seu nexo metafórico: impressão mental. Por essa perspectiva, podemos inferir que - são imagens da memória, as quais, decalcadas sobre a tela, conduzem-nos a massas de cor intensas, dessa maneira, evocando a memória da infância. Muitas vezes, encontramos nessas telas um horizonte impreciso, em dégradé, com as figuras, vistas em plongé. Nelas a indicação de perspectiva sobre tais planos nos chega pela escala dos elementos dispostos pela superfície sem gravidade, tudo está em suspensão. São aviões, ônibus, lápis, ferramentas, guarda-sóis, nuvens, brinquedos criando um tecido imaginário, uma superfície estampada pelas marcas da memória (Figura $4)$. 


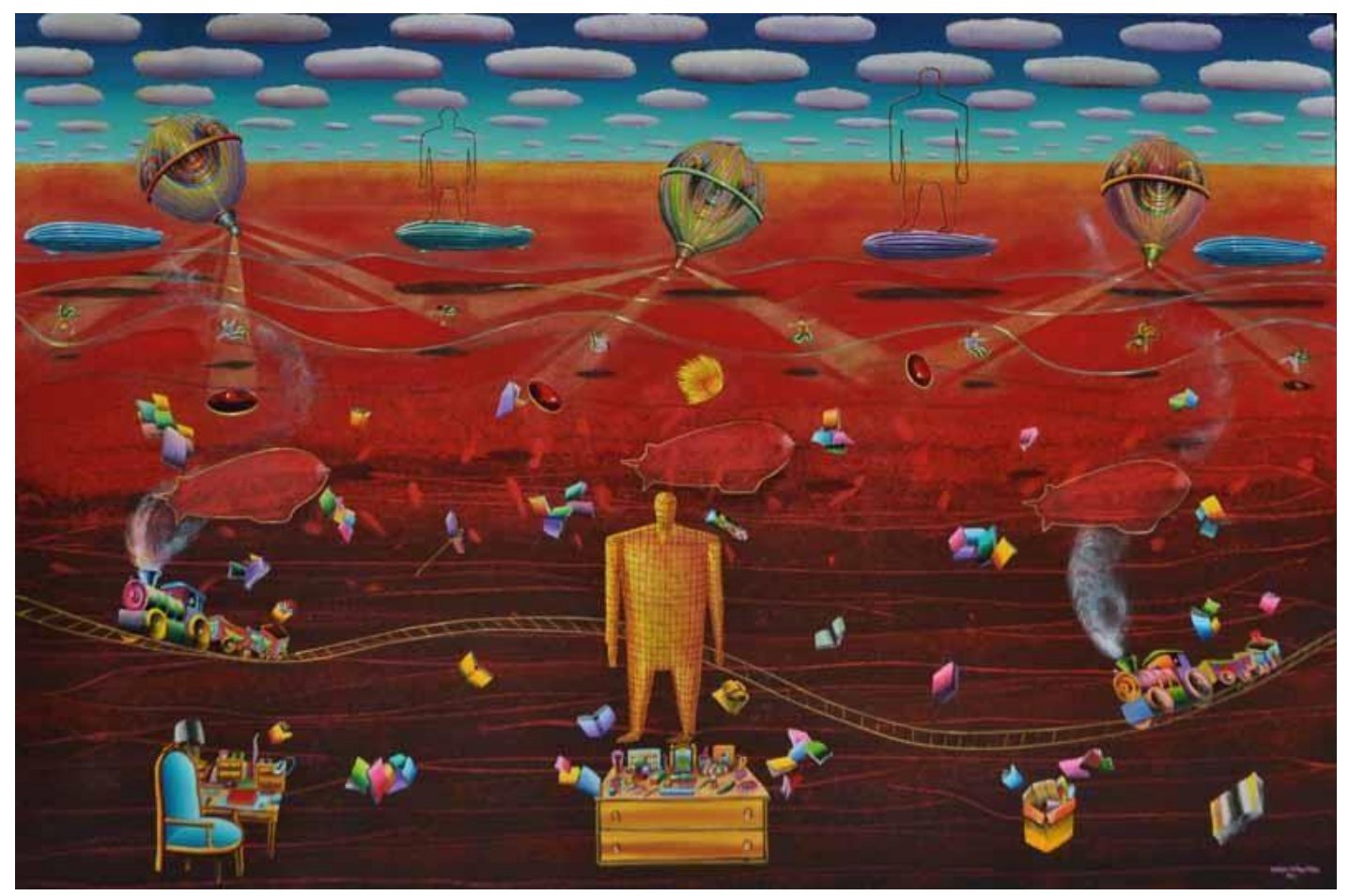

Figura 4. Trens ao vento. 2012. Acrílico sobre tela, $130 \times 195 \mathrm{~cm}$.

Em seu processo de trabalho em ateliê, a impressão, o contato físico entre matriz e suporte, existe como elemento a ser transformado. Podemos pensar que, para o artista que trata a tela da pintura como uma superfície sensível, a etapa de impressão e decalque de formas equivale à obtenção de um negativo que precisa ser revelado. É uma etapa transitiva aberta a sucessivas relações com as camadas de cor que engendram a sua pintura.

\section{Impressão por sublimação}

Trata-se de uma tecnologia que opera através do sistema numérico. Um processo de passagem do estado líquido para o gasoso sem passar pelo estado sólido. $\mathrm{Na}$ impressão sublimática são usadas impressoras jato de tinta para impressão direta em papel transfer e transferência por sublimação em uma prensa a altas temperaturas para o tecido ou outros materiais. Deste modo, as cores que estão na superfície do papel são transferidas, por reação ao calor, às fibras do novo suporte, impregnando-o. Não há como nas técnicas tradicionais de impressão uma relação entre positivos e negativos, cheios e vazios, a transferência que ocorre é de forma para forma e não forma/contraforma ou positivo/negativo.

O que acontece entre a matriz e a imagem final nesta tecnologia? A primeira matriz é um arquivo numérico, um conjunto de dados aspectados como imagens, aquilo que Couchot (2003, p.160) nomeou imagem matriz. "Constata-se então que essas imagens possuem duas características essenciais. Elas são calculadas pelo computador e capazes 
de interagir (ou de "dialogar") com aquele que as cria ou aquele que as olha, "conferindoIhes uma qualidade particular".

Para criar uma imagem numérica, é necessário, inicialmente, criar a matriz matemática correspondente, isto é, efetuar as operações matemáticas que preencherão a memória da imagem. Para este autor, "a estrutura matricial da imagem permite ter acesso diretamente a cada um desses elementos e agir diretamente sobre os seus elementos" (COUCHOT, 2003, p. 161), diferenciando-se de uma imagem tradicional. Ou seja, a imagem possui uma outra natureza de relação técnica com uma realidade preexistente.

A imagem numérica não é mais o registro de um traço deixado por um objeto preexistente pertencendo ao mundo real (traço ótico, no caso da fotografia, do cinema ou do vídeo, ou traço físico resultante do encontro do pincel e da tela na pintura); ela é o resultado de um processo em que a luz é substituída pelo cálculo, a matéria e a energia pelo tratamento da informação (COUCHOT, 2003, p.164).

Podemos referir que o aspecto indiciário nesse sistema não mais se caracteriza pelo traço, a contiguidade física do índice Peirceano assume novas especificidades, a imagem numérica ainda é o registro, porém não mais o registro de um traço, é um registro simulado de um encontro entre objeto e tecnologia.

No caso da sublimação, há um afastamento do contexto de extração, uma distância a ser percorrida entre o arquivo digital e a imagem final: que implica no transporte da informação desde a CPU até a impressora. Até aqui, isto é o mesmo que acontece em qualquer tipo de impressão que opere com tecnologia digital, porém a sublimação comporta mais uma etapa, por isso dizemos que o que acontece é um processo indireto. Há um encadeamento, que gera derivações.

$\mathrm{Na}$ sublimação existem duas espécies de matrizes: a imagem-matriz e a matrizimagem. A primeira é transmitida digitalmente e impressa em Ink Jet sobre o papel transfer, e, nessa operação de imprimir, surge fisicamente a matriz-imagem. Essa matrizimagem, ao ser transferida por sublimação (calor), funde-se com as fibras do tecido, torna-se, assim, irreversível, pois ao impregnar o suporte por contato, tingindo-o, a matriz se desfaz. Aqui até podemos fazer uma analogia com o processo de impressão da matriz perdida ou processo de eliminação de cores, pois ao concluir todas as etapas da imagem impressa, a matriz original está perdida, ou seja, a imagem existe apenas no papel.

A imagem-matriz não necessita passar por um procedimento de contato, talvez não contenha nenhum aspecto indiciário em sua constituição, não tenha surgido de uma fotografia ou escaneamento, tenha sido criada totalmente no ambiente digital, já a matrizimagem - o papel entintado - que transfere a pigmentação ao tecido, guarda, em sua superfície, a marca de cor dos traçados pigmentados que foram sublimados no encontro com o tecido. 


\section{Impressão: sublimação e impregnações pictóricas}

Na impressão por sublimação, realizada por Clóvis Vergara de Almeida Martins Costa, para a série de pinturas expostas na exposição Trazendo aqui pra marte: a ruptura entre a matriz numérica, seu caráter de transitividade e a imagem impressa sobre o tecido contém nessa fenda a fotografia em uma das etapas de seu processo.

Vistas a distância, são seis telas, de $130 \mathrm{~cm} \times 180 \mathrm{~cm}$, aproximadamente, que apresentam imagens com coloração terrosa e estruturadas através de traçados geométricos. Observando atentamente, encontramos sobreposições de fragmentos de cenas de paisagens, permeadas por sutilezas entre as camadas de cor, mescladas pelas marcas de aguadas e de traçados com o pincel. Olhando muito de perto, encontramos a fusão entre a textura da tela e a dos grãos de areia. Paisagem registrada, paisagem apagada (Figuras 5 e 6).

No processo de criação desenvolvido, o artista optou por empregar um tecido de algodão, o que implica na certeza da imprecisão durante a impressão por sublimação e provável desbotamento do mesmo. Além disso, nesta série, a impressão já no tecido passou por outras formas de contato e reimpressão mais sutis e menos técnicas: as imagens fotográficas impressas retornaram à mesma paisagem de onde foram obtidas, para serem, então, impregnadas pelo contato com a água, areia e demais materiais. Realizando, assim, sequências de procedimentos de contato dadas ao acaso, levadas a uma dose de entropia.

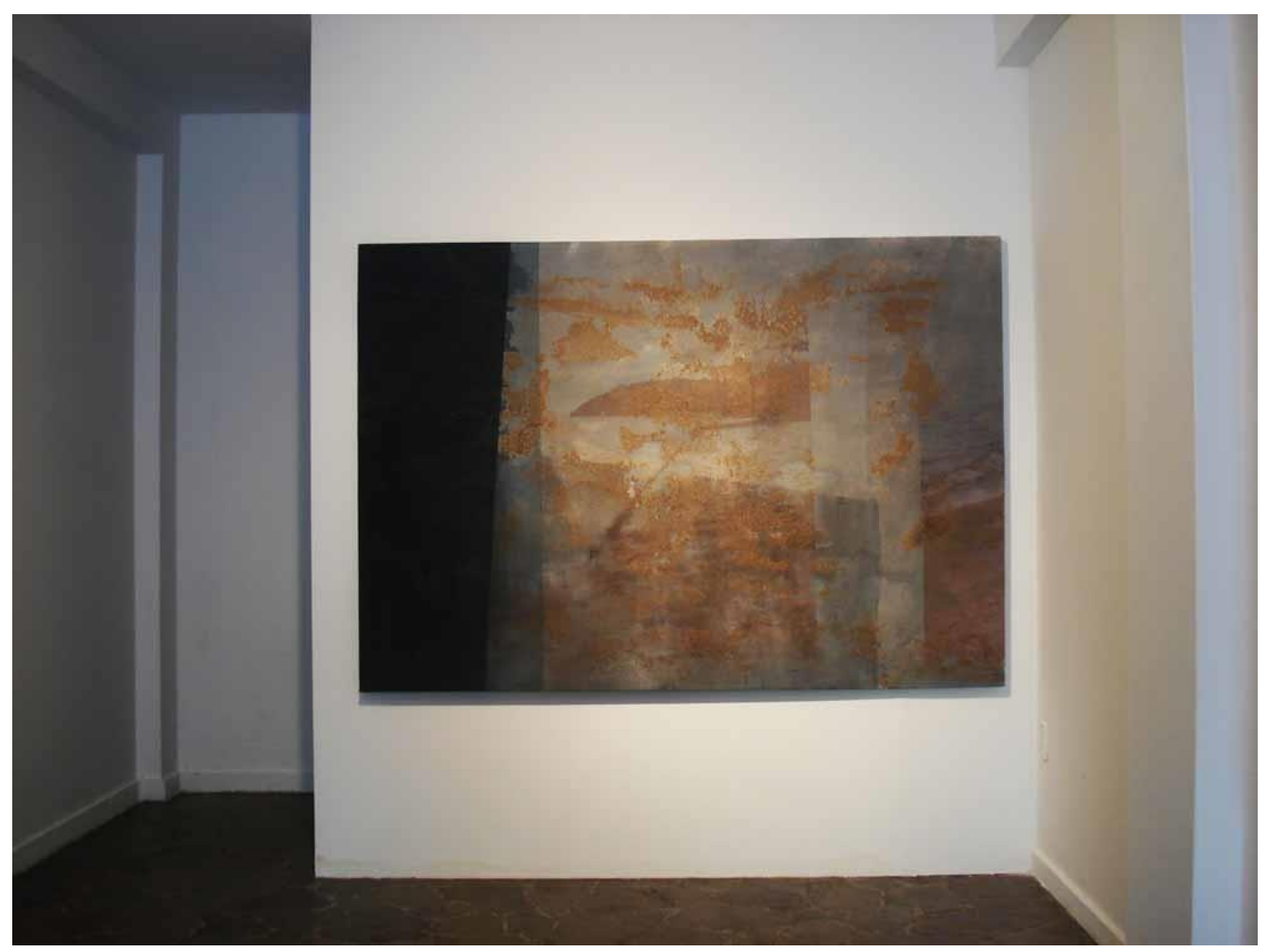

Figura 5. Trazendo aqui pra Marte 2. $2011,130 \times 180 \mathrm{~cm}$. 
A simples disposição do tecido na margem do rio permite que a água e resíduos de matéria orgânica, além de resíduos industriais, infiltrem-se nas fibras, agindo também sobre a pigmentação. As impregnações entre as ocorrências materiais propiciadas pelo contato entre o tecido impresso e a natureza explicitam a sua intenção de incluir a imprevisibilidade como um elemento significativo no processo. Imprevisibilidade articulada em comunhão com a experiência de estar à margem, desdobrando a ação em registros fotográficos, videográficos e textos. São múltiplas as transitividades agregadas às imagens impressas nesse processo.

Para Clovis Vergara de Almeida Martins Costa:

"A investigação deste trânsito de procedimentos, imagens e superfícies implica a reflexão acerca de suas dimensões simbólicas, objetuais e afetivas. Opero, desta forma, ações em espaços determinados, territórios onde o aporte de imagens e matéria (areia, água, tinta, pigmentos) adensa e constitui o campo da pintura. Problematizo aqui também a condição da pintura enquanto meio ao distender suas possibilidades de ativação através da hibridização com a fotografia. A pintura como superfície resultante de distintos procedimentos de contato, acumula vestígios de ocorrências, materializando, portanto, o caráter indicial destes vetores de força: ação, impregnação, impressão e elaboração do campo pictórico, através de lavagens de cor (refiro-me aqui ao procedimento de destacar e elaborar planos por meio de transparências e filtros de cor, banhando a superfície com tinta acrílica diluída.). Intensidades são reveladas através de camadas que adensam e inflexionam o tecido, construindo campos de cor que escondem ou revelam as estruturas do composto ação/imagem/superfície. Signos de uma temporalidade submersa, as imagens fornecem pistas sobre o local de origem e acionam zonas de contato entre superfícies distintas: margens de rio, fotografia e pintura". ${ }^{4}$

Nos procedimentos empregados por Martins Costa, o trânsito entre as operações da tecnologia de impressão por sublimação e de processos de pintura, a fotografia é um dos elementos ativadores do processo. É uma forma de contatar a paisagem, de recortála, manipulá-la. É uma etapa intermediária, a imagem impressa, por sua vez, torna-se o fundo da pintura.

\footnotetext{
${ }^{4}$ Entrevista à Lurdi Blauth, Novo Hamburgo. Primeiro semestre de 2012.
} 


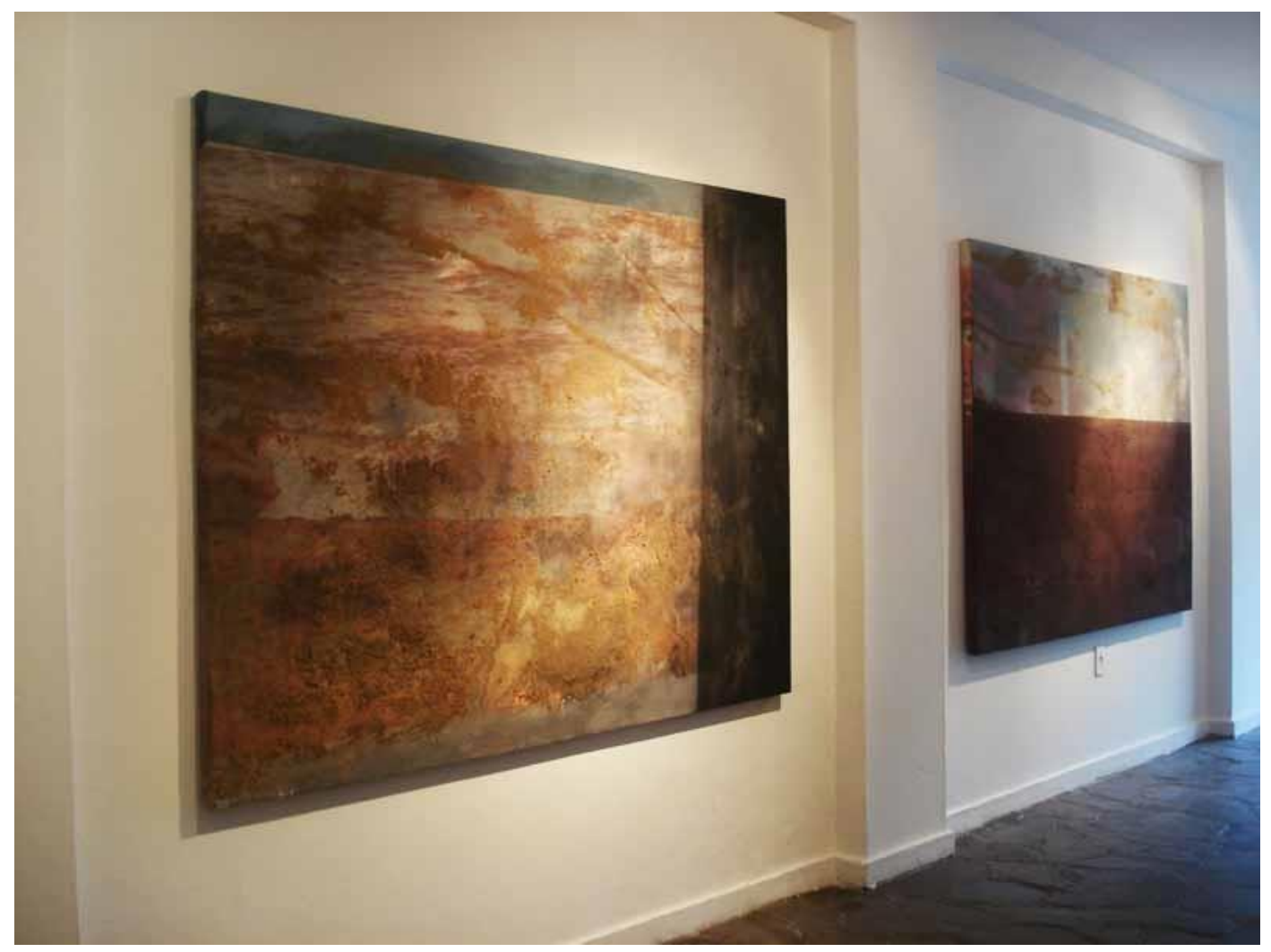

Figura 6. Trazendo aqui pra Marte 3 e $4.2011,130 \times 180 \mathrm{~cm}$.

Nesse sentido, poderíamos pensar onde se situa o punctun dessas imagens? Conforme Roland Barthes propõe no livro Câmara Clara (1984) - a atenção estaria identificada num detalhe da fotografia. O que certamente não ocorre na pintura de Martins Costa, pois somos levados a buscar outras evidências nas imagens. Ou seja, pensar no conceito de rizoma proposto por Deleuze e Guatarri (1995) - como uma rede de conexões, onde não há mais um centro, mas qualquer ponto pode conectar-se a outro numa relação infinita de novas possibilidades. A interpenetração de uma multiplicidade de camadas deflagra o desvelamento de sentidos que remetem a uma certa mobilidade, porém sem hierarquia. Nesse aspecto, os diversos elementos que constituem essas pinturas propiciam essa forma rizomática, "que é inclusiva e infinita. Ela é fluída, pode escorregar entre os elementos, manifestando-se nos aspectos mais inesperados [...], em suas fissuras e vãos" (CATTANI, 2007, p. 27).

Nessas relações, elaboram-se os sentidos que não se encontram nos elementos em si, mas nessa mutabilidade e mobilidade dos entre-lugares, entre-formas, ou seja, o punctun se situa nesse espaço entre - que se desdobra e se expande, e que não encontra um lugar fixo. Para Cattani, dos sentidos desses elementos situados no entre, surge a diferença sem lugares fixos, e o punctum pode ser constituído "no vazio entre dois pontos" (2007, p.27) nesse deslocamento de sentidos. 


\section{Outras considerações}

A partir dessas considerações e reflexões sobre as possibilidades empregadas em diferentes procedimentos de contato, percebemos que os processos de impressão são ambivalentes em relação aos seus aspectos de contato, produzindo um duplo significado: de um lado, o contato conduz à semelhança óptica e tátil da matriz; e, de outro, a impressão impõe, retira a semelhança do corpo do qual ela se apoderou. Por isso, ela é predadora, guarda a perda, a ausência, no instante da sua captura, revelando na semelhança, a memória desse momento do contato (DIDI-HUBERMAN, 2008). Contudo, para que uma impressão apareça naquilo que resulta, é preciso que algo toque, afundese na matéria, registrando uma presença, uma marca, ao mesmo tempo, é necessário o afastamento, a ausência. Cada impressão é singular e está impregnada de um entrelaçamento que remete à dupla relação entre a potência e a fragilidade.

Aí podemos nos perguntar: o que ocorre com as impressões resultantes de matrizes numéricas? Talvez pudéssemos pensar que as novas tecnologias interpõem vínculos de outro gênero com a imagem. Nos processos numéricos, as informações são limitadas nas possibilidades expressas na linguagem do computador, ou seja,

[...] ele é incapaz de compreender o menor gesto. Se ele interpreta sem erro o toque do dedo no teclado, é porque a cada toque corresponde um valor numérico codificado que ele traduz automaticamente em uma letra ou uma cifra, segundo um código apropriado, que transforma esses valores em pixels (COUCHOT, 2003, p.170-171).

Mas isso não significa que os processos artísticos que empregam o sistema numérico restrinjam-se aos limites da tecnologia, na atualidade, os artistas têm a possibilidade de cruzar técnicas rudimentares de impressão com as novas tecnologias, miscigenando ações físicas e operações digitais.

As experimentações de impressão observadas nos processos de criação no presente texto incluíram a utilização de matrizes de cobre e os desdobramentos através de diferentes meios de impressão convencional, passando pela fotografia até as transposições para impressão com meios digitais. Entre as tecnologias de impressão experimentadas, está a sublimação, sobre a qual tratamos de algumas considerações.

Dessa forma, nessa etapa de nossa pesquisa (primeiro semestre de 2012), investigamos a pós-produção dos arquivos de imagens e procuramos analisar e comparar as características dos diferentes tipos de impressão sobre distintos suportes materiais. Observamos de que modo nós e outros artistas atingimos nossas intenções articulando técnicas manuais, químicas e mecânicas com as possibilidades oferecidas pelas novas tecnologias dos meios de reprodução. 
Assim, percebemos que o valor heurístico da impressão está acoplado ao seu valor de experimentação aberta, que amplia as possibilidades de produzir novos sentidos de uma apreensão do mundo. A introdução de novos meios e materiais é resultante dos avanços tecnológicos de cada época, cujas diferentes características interferem na maneira de pensar e criar. Podemos inferir que o material utilizado em diferentes meios de impressão envolve um processo dialético, de um lado, possibilitam ao artista modificar simbolicamente a sua matéria para construir uma imagem; e, de outro, as diferentes características interferem e se constituem como parte da obra.

\section{REFERÊNCIAS}

BARTHES, Roland. A câmara clara. Rio de Janeiro: Nova Fronteira, 1984.

BLAUTH, Lurdi. Marcas, passagens e condensações. Porto Alegre, RS: Editora da UFRGS, 2011.

CATTANI, Iclea (Org.). Mestiçagens na arte contemporânea. Porto Alegre, RS: Editora da UFRGS, 2007.

COUCHOT, Edmond. A tecnologia na arte: da fotografia à realidade virtual. Porto Alegre, RS: Editora da UFRGS, 2003.

DELEUZE, Gilles; GUATTARI, Félix. Mil Platôs. São Paulo: 34, 1995. v.1.

DIDI-HUBERMAN, Georges. La ressemblance par contact. Paris: Minuit, 2008. . L'Empreinte - Catálogo de exposição. Tradução de Patrícia Franca. Paris: Centre

Georges Pompidou, 1997.

SCHAEFFER, Jean-Marie. A imagem precária. Campinas: Papirus, 1996.

Lurdi Blauth (Feevale)

Elaine Tedesco (UFRGS)

Recebido em: 30/10/2012

Aprovado em: 10/01/2013 